\title{
Cholesterol Synthesis and De Novo Lipogenesis in Premature Infants Determined by Mass Isotopomer Distribution Analysis
}

\author{
LORRAINE N. RENFURM, ROBERT H.J. BANDSMA, HENKJAN J. VERKADE, \\ CHRISTIAAN V. HULZEBOS, THEO VAN DIJK, THEO BOER, FRANS STELLAARD, \\ FOLKERT KUIPERS, AND PIETER J.J. SAUER
}

Groningen University Institute for Drug Exploration, Center for Liver, Digestive and Metabolic Diseases, Department of Pediatrics, University Hospital Groningen, 9700 RB Groningen, The Netherlands \begin{abstract}
ABS
Premature infants change from placental supply of mainly
carbohydrates to an enteral supply of mainly lipids earlier in their development than term infants. The metabolic consequences hereof are not known but might have long-lasting health effects. In fact, knowledge of lipid metabolism in premature infants is very limited. We have quantified de novo lipogenesis and cholesterogenesis on d 3 of life in seven premature infants (birth weight, $1319 \pm 417 \mathrm{~g}$; gestational age, $30 \pm 2$ wk). For comparison, five healthy adult subjects were also studied. All subjects received a $12-\mathrm{h}\left[1-{ }^{13} \mathrm{C}\right]$ acetate infusion, followed by mass isotopomer distribution analysis (MIDA) on lipoproteinpalmitate and plasma unesterified cholesterol. The fraction of lipoprotein-palmitate synthesized at the end of the infusion period was $5.4 \pm 3.9 \%$ in infants, which was in the same range as found in adult subjects on a normal diet, suggesting that hepatic
\end{abstract}

de novo lipogenesis is not a major contributor to fat accumulation in these premature neonates. The fractional contribution of newly synthesized cholesterol to plasma unesterified cholesterol was $7.4 \pm 1.3 \%$ after a $12-\mathrm{h}$ infusion. The calculated rate of endogenous cholesterol synthesis was $31 \pm 7 \mathrm{mg} / \mathrm{kg} / \mathrm{d}$, a value approximately three times higher than that found in adult subjects $(10 \pm$ $6 \mathrm{mg} / \mathrm{kg} / \mathrm{d})$. These results indicate that the cholesterolsynthesizing machinery is well developed in premature infants. (Pediatr Res 56: 602-607, 2004)

\section{Abbreviations}

AGA, appropriate size for gestational age MIDA, mass isotopomer distribution analysis

SGA, small for gestational age

VLDL, very-low-density lipoproteins
The highest growth rate in a human life span occurs during the fetal period. During this rapid growth, the fetus requires significant amounts of cholesterol and fatty acids that may be acquired from maternal sources or synthesized de novo by the fetus itself. The relative contribution of either source is not known. Cholesterol is required for structural functions and as a precursor of various metabolically active compounds such as hormones, oxysterols, and bile salts. Inborn errors in cholesterogenesis lead to severe congenital defects, such as the Smith-Lemli-Opitz syndrome (SLO), indicating that maternal supply cannot fully account for the demands during fetal development. Recently, it was demonstrated that newly syn-

Received May 6, 2003; accepted April 14, 2004.

Correspondence: Folkert Kuipers, Ph.D., Groningen University Institute for Drug Exploration, Center for Liver, Digestive and Metabolic Diseases, Laboratory of Pediatrics, University Hospital Groningen, Hanzeplein 1, 9700 RB Groningen, The Netherlands; e-mail: f.kuipers@med.rug.nl

Supported by the Netherlands Organization for Scientific Research (NWO, grant 920-03-123).

L.N.R. and R.H.J.B. equally contributed to this work.

DOI: 10.1203/01.PDR.0000139482.88468.46 thesized cholesterol activates Sonic hedgehog (Shh) (1), a signaling protein essential for normal embryonic development, which delineates the importance of this metabolic pathway.

Fatty acids are needed as structural components of membrane phospholipids, as a source of energy, and, if metabolic regulation in the fetus is similar to that in the adult, as activators of specific transcription factors $(2,3)$. Most observations suggest that in early gestation these fatty acids are derived from maternal sources after crossing the placenta, followed by a gradual shift to de novo synthesis in fetal tissues with advancing gestation (4-7). Hepatic lipogenesis is quantitatively not important in adult human life in industrialized societies. However, it has been suggested to be of importance in the fetus (8). No experimental data exist to indicate that hepatic de novo lipogenesis is a major contributor to the fetal lipid accumulation normally observed in the third trimester of pregnancy.

Because fat deposition and accretion of specific lipids occurs mainly during the last trimester of intrauterine development, the prematurely born neonate is prone to be deficient in specific metabolites (e.g. brain docosahexaenoic acid and carnitine) as 
well as in the enzymes needed for fat digestion and metabolism. Furthermore, one of the most important differences in fat metabolism between premature and term neonates is that the very low birth weight neonate is often maintained on total parenteral nutrition for substantial periods of time after birth. Most parenteral nutrition solutions do not contain cholesterol. Breast milk does contain significant quantities of cholesterol. However, it is evident that many human infants thrive on cholesterol-poor formulas. It is not clear whether or to what extent cholesterol neosynthesis compensates for variations in dietary cholesterol intake in premature infants. There are indications to suggest relationships between the developmental stage at birth, the type and duration of infant feeding, and susceptibility to develop chronic diseases in adulthood, such as atherosclerosis and insulin-dependent diabetes mellitus $(9,10)$. The mechanism underlying these long-lasting effects of early nutrition are not known but may be related to the amount of cholesterol ingested and/or the fatty acid quality and quantity during specific, critical periods of development.

The aim of this study was to gain insight in the contribution of hepatic de novo lipogenesis to overall lipid accumulation in premature infants. In addition, we set out to determine the rate of cholesterogenesis in premature infants without a substantial dietary cholesterol intake. We quantified both processes in vivo using stable isotope labeling of plasma cholesterol and lipoprotein-palmitate with $\left[1-{ }^{13} \mathrm{C}\right]$ acetate, followed by MIDA. These results provide the background information that is essential for studies on the metabolic consequences of composition of enteral and parenteral nutrition in this specific group of patients.

\section{MATERIALS AND METHODS}

Patients and study design. Seven premature infants were studied (birth weight, $1319 \pm 417 \mathrm{~g}$; gestational age, $30 \pm 2$ wk) (Table 1), starting $2 \mathrm{~d}$ after birth. All infants required mechanical ventilation and were admitted to the neonatal intensive care unit of the Beatrix Children's Hospital in Groningen immediately after birth. The infants received parenteral feeding, which was initiated at $24 \mathrm{~h}$ after birth with a glucose intake of about $6-7 \mathrm{mg} / \mathrm{kg} / \mathrm{min}$ during the time of the experiments. Parenteral feeding also included a lipid emulsion (Lipofundin 20\%, Fresenius Kabi, Bad Homburg, Germany) that was infused at a rate of $0.8 \mathrm{~g} / \mathrm{kg} / \mathrm{d}$ at the second day of life. A very limited enteral feeding schedule $(7.0 \pm 2.7 \mathrm{~mL} / \mathrm{d})$ was initiated on the day of the $\left[1-{ }^{13} \mathrm{C}\right]$ acetate infusion. The ingested amount of cholesterol via the enteral route was $<3 \mathrm{mg} / \mathrm{d}$ and the amount of carbohydrates via the enteral route was $<0.5$ $\mathrm{mg} / \mathrm{kg} / \mathrm{min}$ during the time of the experiment. All mothers except one (patient 5) had received antenatal steroids. The experimental protocol did not interfere with standard treatment for this group of patients. Exclusion criteria were as follows: congenital infection, metabolic disorders, maternal endocrine disorders (diabetes and thyroid disorders), and chromosomal abnormalities. Patients received a constant i.v. infusion of $\left[1-{ }^{13} \mathrm{C}\right]$ acetate (Isotec, Miamisburg, OH) at a rate of 0.20 $\mathrm{mmol} / \mathrm{kg} / \mathrm{h}$ for $12 \mathrm{~h}$. The start of the study $(\mathrm{t}=0)$ was defined by the start of $\left[1-{ }^{13} \mathrm{C}\right]$ acetate infusion. Blood samples of 0.5 $\mathrm{mL}$ arterial blood were taken before and $8,10,11$, and $12 \mathrm{~h}$ after start of the infusion (incorporation phase), and subsequently at $2,4,6,10,21,30$, and $45 \mathrm{~h}$ after termination of the infusion (decay phase). The study protocol was approved by the Central Committee on Research Involving Human Subjects, the Netherlands, and written informed consent was obtained from the parents after the protocol had been fully explained.

For comparison, five healthy adult control subjects were studied (mean age, $32 \pm 15 \mathrm{y}$; weight, $64 \pm 7 \mathrm{~kg}$ ). All subjects were instructed to consume their regular diet until $2200 \mathrm{~h}$ of the evening of the start of the study, at which time they started their fast till $0900 \mathrm{~h}$. At this time, they received an oral liquid diet replacement (Nutridrink, Nutricia BV, The Netherlands) containing $39 \%$ of total energy as fat with no cholesterol, $13 \%$ as protein and $48 \%$ as carbohydrates, at an ingestion rate of 7 $\mathrm{mg} / \mathrm{kg} / \mathrm{min}$ of carbohydrates. At midnight, a $\left[1-{ }^{13} \mathrm{C}\right]$ acetate infusion $(0.20 \mathrm{mmol} / \mathrm{kg} / \mathrm{h})$ was started for $12 \mathrm{~h}$. Venous blood samples were taken before and $8,10,11$, and $12 \mathrm{~h}$ after start of the infusion (incorporation phase), and subsequently at 1, 2, 4, $6,18,26,42,50,66$, and $74 \mathrm{~h}$ after termination of the infusion (decay phase). After cessation of the infusion, subjects were allowed their normal dietary intake.

Analytical procedure. Blood was collected from the patients and volunteers in EDTA tubes and was directly centrifuged to separate plasma and cells. The plasma was stored at $-80^{\circ} \mathrm{C}$ until further processing. Cholesterol for gas chromatography/ mass spectrometry (GC/MS) analysis was extracted from 100 $\mu \mathrm{L}$ of plasma with $2 \mathrm{~mL}$ of $95 \%$ ethanol/acetone (1:1, vol/vol) according to Neese et al. (11). Unesterified cholesterol was subsequently derivatized using $\mathrm{N}, \mathrm{O}$-bis-(trimethyl)trifluoroacetamide with $1 \%$ trimethylchlorosilane at room temperature. Samples were dried under nitrogen and dissolved in $500 \mu \mathrm{L}$ of hexane. Triacylglycerol-rich lipoproteins were isolated from plasma by ultracentrifugation as described earlier (12). VLDL separated using this method does also include intermediate-

Table 1. Characteristics of premature infants

\begin{tabular}{ccccccc}
\hline Patient no. & Gender & Gestational age (wk) & Birth weight (g) & Percentile (\%) & Age at start of study (h) & Cholestero (mmol/L) \\
\hline 1 & M & 30 & 1240 & P10-25 & 50 & 49 \\
2 & M & 30 & 1435 & P25-50 & 2.82 \\
3 & M & 30 & 1315 & P10-25 & 49 & 2.01 \\
4 & F & 29 & 845 & P5-10 & 43 & 0.89 \\
5 & F & 34 & 1785 & P25-50 & 42 & 1.28 \\
6 & F & 30 & 1845 & P50-90 & 53 & 1.32 \\
7 & M & 29 & 765 & & 50 & 7.16 \\
Mean & & 30.4 & 1319 & & & 7 \\
SD & & 1.5 & 417 & & & 054 \\
\hline
\end{tabular}


density lipoproteins (IDL) and potentially chylomicrons. Lipids were extracted from lipoprotein fractions with $2 \mathrm{~mL}$ methanol/hexane $(4: 1, \mathrm{vol} / \mathrm{vol})$ and transmethylated to fatty acidmethyl esters using acetyl chloride. Samples were dried under nitrogen and dissolved in $100 \mu \mathrm{L}$ hexane. Lipoprotein particle size was calculated according to Beil and Grundy (13), using the formula $\mathrm{D}=(0.211 \cdot([\mathrm{TG}] /[\mathrm{PL}])+0.38) / 0.0213$, in which $\mathrm{D}$ is the diameter in $\AA$. Assay kits for determination of plasma and lipoprotein triglyceride and cholesterol concentrations were obtained from Hoffmann-La Roche Ltd (Basel, Switzerland) and for determination of lipoprotein phospholipid concentrations from Waco Chemical (Marburg, Germany).

Enrichments of lipoprotein-palmitate and of cholesterol were measured by GC/MS. Cholesterol trimethylsilylether derivatives were separated with an HP 5890 Plus gas chromatograph (Hewlett-Packard, Palo Alto, CA), using a $30 \mathrm{~m} \times 0.25$ $\mathrm{mm}(0.2 \mu \mathrm{m}$ film thickness) DB5 ms column (J\&W Scientific, Falson, CA) directly inserted into the ion source of a Quadrupole mass spectrometer, model SSQ 7000 (Finnigan Matt, San Jose, CA). The oven temperature was programmed from 150 to $320^{\circ} \mathrm{C}$ at $30^{\circ} / \mathrm{min}$. A splitless injection was applied. The mass fragments $\mathrm{m} / \mathrm{z} 368,369,370$, and 371 were monitored by selected ion recording using chemical ionization. For analysis of the methyl esters of lipoprotein-palmitate, the same GC/MS mode as described above was used, equipped with a $20 \mathrm{~m} \times$ $0.18 \mathrm{~mm}$ i.d. AT1701 column (0.4 $\mu \mathrm{m}$ film thickness, Alltech Associates Inc., Deerfield, IL). GC oven temperature increased from $100^{\circ} \mathrm{C}$ to $280^{\circ} \mathrm{C}$ at $20^{\circ} \mathrm{C} / \mathrm{min}$. They were analyzed at mass-to-charge ratio $(\mathrm{m} / \mathrm{z}) 271,272$ and 273 (mass isotopomers $\mathrm{M}^{0}, \mathrm{M}^{1}$, and $\mathrm{M}^{2}$ ) using chemical ionization and selected ion recording, with methane as moderating gas.

Calculations. The theoretical background of the MIDA technique is described in detail elsewhere $(14,15)$. MIDA is a method for calculating the fraction of newly synthesized polymers and the isotope enrichments of their monomer precursor subunits in vivo during a stable isotope labeling experiment. By applying probability logic with mass spectrometric analysis of polymers, the enrichment of the precursor pool (acetyl-CoA) and the fractional biosynthetic rates of the polymer can be calculated. This technique allows us to determine the fraction of newly synthesized cholesterol and palmitate molecules in the plasma pool. After cessation of label incorporation, the rate constant of decay of cholesterol is determined by analyzing enrichments of the higher isotopomers to exclude the chance of continuing label incorporation. It then becomes possible to calculate absolute cholesterol synthesis rates, using an estimate of body unesterified cholesterol pool size. An estimation of 130 $\mathrm{mg} / \mathrm{kg}$ body weight for the total body unesterified cholesterol pool was used, as proposed by Neese et al. (11), to calculate absolute synthesis rates. The "rapidly miscible" cholesterol pool supposedly includes liver, intestine, and plasma. The following non-steady-state equation is used: $K=k \times f \times$ pool size/ $\left(1-\mathrm{e}^{-k t}\right)$, where $K(\mathrm{mg} / \mathrm{kg} / \mathrm{h})$ is the absolute rate of cholesterol synthesis, $f$ (in \%) is the fraction of newly synthesized cholesterol molecules, and $k\left(\mathrm{~h}^{-1}\right)$ is the rate constant of isotopic cholesterol removal from plasma. Curves for the excess of isotopomer $\mathrm{M}+3$ in premature infants and control subjects are shown in Figure 1. The 12-h blood sample was

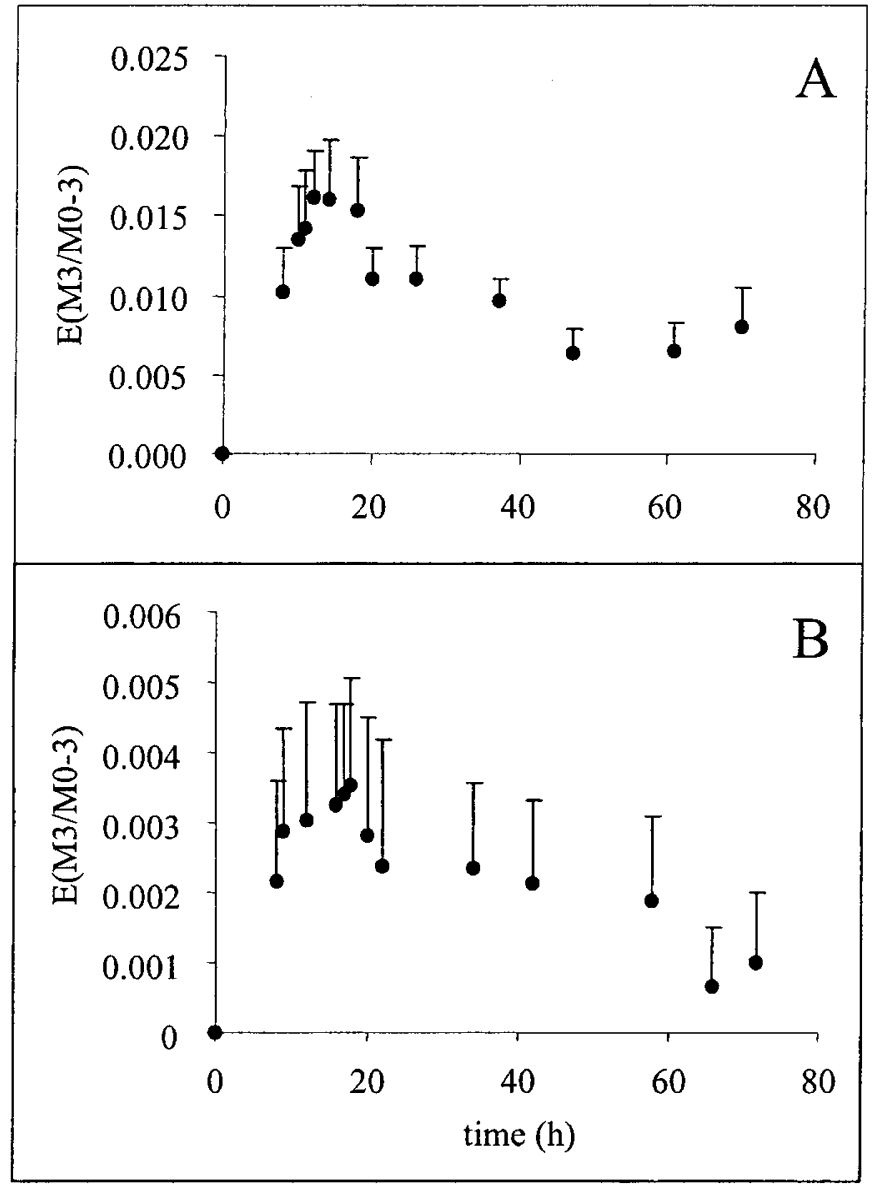

Figure 1. Excess of isotopomer $\mathrm{M}+3$ after start of the infusion with $\left[1-{ }^{13} \mathrm{C}\right]$ acetate for premature infants $(A)$ and control subjects $(B)$.

used for calculation of fractional synthesis rates of both cholesterol and lipoprotein-palmitate. Blood samples taken 1-72 h after cessation of the infusion, the so-called decay phase, were used to calculate $k$.

Statistical analysis. All values are expressed as means \pm SD. Significance of differences was calculated using the twotailed $t$ test for normally distributed unpaired data or a MannWhitney $U$ test for data that were not normally distributed. A $p$ value $<0.05$ was considered significant.

\section{RESULTS}

The clinical characteristics of the infants are shown in Table 1. All the infants were AGA, except for patients 4 and 7, who were SGA. The mean age of the infants at start of the study was $50 \pm 7 \mathrm{~h}$.

The fractions of circulating unesterified cholesterol $(f)$ attributable to endogenous synthesis are shown in Table 2. After a 12 -h infusion of ${ }^{13} \mathrm{C}$-labeled acetate, $7.4 \pm 1.3 \%$ of plasma unesterified cholesterol was derived from acetyl-CoA in the premature infants and $3.2 \pm 1.5 \%$ in the adults. The fractional rate constant of decay $(k)$ of endogenously labeled plasma cholesterol was $0.08 \pm 0.02 \mathrm{~h}^{-1}$. This was not significantly different from the rate constant calculated for adults: $0.05 \pm$ $0.04 \mathrm{~h}^{-1}$. Endogenous cholesterol synthesis was $39.9 \pm 10.8$ $\mathrm{mg} / \mathrm{d}$ or $31.2 \pm 7.2 \mathrm{mg} / \mathrm{kg} / \mathrm{d}$ in infants. Cholesterol synthesis 
Table 2. Cholesterol synthesis rates in premature infants

\begin{tabular}{|c|c|c|c|c|c|}
\hline Patient & $\mathrm{p}(\%)$ & $\mathrm{f}(\%)$ & $\mathrm{k}\left(\mathrm{h}^{-1}\right)$ & $\mathrm{K}(\mathrm{mg} / \mathrm{d})$ & $\mathrm{K}(\mathrm{mg} / \mathrm{kg} / \mathrm{d})$ \\
\hline 1 & 16.7 & 8.4 & 0.06 & 45.5 & 36.0 \\
\hline 2 & 16.7 & 8.8 & 0.07 & 50.9 & 39.0 \\
\hline 3 & 15.0 & 6.6 & 0.06 & 35.99 & 27.3 \\
\hline 4 & 10.7 & 8.6 & 0.12 & 34.7 & 41.0 \\
\hline 5 & 13.7 & 7.1 & 0.07 & 50.9 & 28.5 \\
\hline 6 & 13.3 & 5.6 & 0.07 & 40.8 & 22.1 \\
\hline 7 & 12.7 & 6.4 & 0.07 & 20.4 & 26.7 \\
\hline Mean \pm SD infants & $14.1 \pm 2.2$ & $7.4 \pm 1.3$ & $0.08 \pm 0.02$ & $39.9 \pm 10.8$ & $31.2 \pm 7.3$ \\
\hline Mean \pm SD adults & $10.3 \pm 3.8^{*}$ & $3.2 \pm 1.5^{*}$ & $0.05 \pm 0.04$ & $593 \pm 287$ & $9.8 \pm 6.2 *$ \\
\hline
\end{tabular}

Infusions of $\left[1-{ }^{13} \mathrm{C}\right]$ acetate and analysis of plasma unesterified cholesterol by GC-MS were performed as described in the text. p, isotopic enrichment of

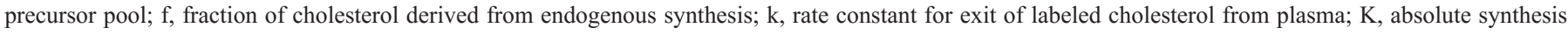
rate of plasma cholesterol. Values are expressed as mean $\pm \mathrm{SD}$.

* Denotes significant difference $(p<0.05)$ from premature infants.

rates were $9.8 \pm 6.2 \mathrm{mg} / \mathrm{kg} / \mathrm{d}$ in adults. Thus, when normalized for body weight, cholesterol synthesis in premature infants was more than three times higher than in adults (Fig. 1).

The enrichments of the hepatic acetyl-CoA precursor pools $(p)$ and the fractional contribution $(f)$ of de novo lipogenesis to lipoprotein-palmitate are summarized in Table 3. The fraction of de novo lipogenesis was $5.4 \pm 3.9 \%$ in the premature infants and $2.3 \pm 2.9 \%$ in the healthy adult subjects after a 12 -h infusion. There were no differences between calculated cholesterol and lipoprotein-palmitate precursor acetyl-CoA enrichments in both subject groups (compare Tables 2 and 3). However, acetyl-CoA enrichments were significantly higher in infants than in adults who received $\left[1-{ }^{13} \mathrm{C}\right]$ acetate at similar infusion rates.

The isolated lipoprotein fractions contained on average $58.0 \pm 13.6 \%$ triglycerides, $27.9 \pm 10.6 \%$ phospholipids, and $13.7 \pm 7.1 \%$ total cholesterol (Table 4 ). The two premature SGA infants (patients 4 and 7) showed higher triglyceride contents of their lipoprotein particles than the AGA infants, and, consequently, lower phospholipid and cholesterol contents. The calculated lipoprotein particle size of the two SGA infants was larger than those of the AGA infants (Table 4).

Table 3. De novo lipogenesis in lipoprotein-palmitate in premature infants

\begin{tabular}{ccc}
\hline & \multicolumn{2}{c}{ Lipoprotein } \\
\cline { 2 - 3 } Patient & $\mathrm{p}(\%)$ & $\mathrm{f}(\% / 12 \mathrm{~h})$ \\
\hline 1 & 15.6 & 2.5 \\
2 & 10.8 & 2.8 \\
3 & 18.3 & 0.9 \\
4 & 11.9 & 11.6 \\
5 & 10.0 & 6.6 \\
6 & 11.6 & 9.3 \\
7 & 16.7 & 3.9 \\
Mean \pm SD infants & $13.6 \pm 3.2$ & $5.4 \pm 3.9$ \\
Mean \pm SD adults & $9.1 \pm 3.3 *$ & $2.3 \pm 2.9$ \\
\hline
\end{tabular}

Stable isotope infusions and GC-MS analysis of palmitate-methyl ester from plasma lipoproteins were performed as described in the text. p, enrichment of precursor acetyl-CoA subunits that entered newly synthesized lipoproteinpalmitate molecules; f, fraction of circulating lipoprotein-palmitate derived from endogenous synthesis. Values are expressed as mean $\pm \mathrm{SD}$.

* Denotes significant difference $(p<0.05)$ from premature infants.
Table 4. Composition and particle size of lipoproteins in premature infants

\begin{tabular}{ccccc}
\hline Patient no. & TG $(\%)$ & PL $(\%)$ & TC $(\%)$ & Particle size $(\mathrm{nm})$ \\
\hline 1 & 56.1 & 36.5 & 7.4 & 33.1 \\
2 & 51.7 & 35.3 & 13.0 & 32.4 \\
3 & 38.3 & 43.8 & 17.9 & 26.5 \\
4 & 77.5 & 18.5 & 4.1 & 59.4 \\
5 & 56.7 & 21.4 & 21.8 & 44.1 \\
6 & 51.8 & 23.5 & 21.8 & 39.7 \\
7 & 74.1 & 16.2 & 9.7 & 63.2 \\
Mean & 58.0 & 27.9 & 13.7 & 42.6 \\
SD & 13.6 & 10.6 & 7.1 & 14.0 \\
\hline
\end{tabular}

Patients 4 and 7 are SGA. TG, triglycerides; PL, phospholipids; TC, total cholesterol.

\section{DISCUSSION}

This study was designed to quantify the rates of cholesterolgenesis and de novo lipogenesis in premature infants. The results of this study show that cholesterol synthesis in premature infants is relatively high, i.e., three times higher than in adults, during the first days of life. Hepatic de novo lipogenesis in lipoprotein-palmitate was relatively low in premature infants and similar to values reported in adults in this study and by others $(15,16)$.

The MIDA method has several advantages for the specific purposes of this study. First, precursor pool enrichments (acetyl-CoA) are calculated from the labeling pattern of the end products, i.e. cholesterol and fatty acids, which provides a highly accurate basis for calculation of actual synthesis rates. For instance, $\left[\mathrm{U}_{-}{ }^{13} \mathrm{C}\right]$ glucose has been used to calculate fractional synthetic rates of palmitate in humans (17), which may underestimate the rate of de novo lipogenesis due to isotopic dilution in the precursor pool between plasma glucose and the precursor acetyl CoA pool. Another advantage of MIDA is that it allows the use of small blood samples $(0.2-0.5 \mathrm{~mL})$. For determination of the lipoprotein-palmitate enrichments, only two samples of $1.0 \mathrm{~mL}$ blood were needed. For comparison, the deuterium incorporation method that also allows for quantification of fractional synthesis rate of cholesterol and palmitate requires blood samples of $8 \mathrm{~mL}(18-21)$. Di Buono et al. (21) demonstrated that the deuterium incorporation technique and MIDA for measurement of cholesterol synthesis in humans yielded comparable results for fractional and absolute cholesterol synthesis rates. It should be realized that MIDA calculates 
the amount of cholesterol in liver, erythrocytes, and plasma (11) that is derived from endogenous synthesis over the course of the infusion period. The total body cholesterol synthesis is not measured, because tissue cholesterol synthesis that does not leave the cell or equilibrates with the plasma compartment will not be measured. This may lead to a certain degree of underestimation. The estimate of the unesterified cholesterol pool size, which is derived from a value calculated for adults (11), may lead to underestimation of absolute cholesterologenesis in premature infants. For practical reasons, we selected a $130 \mathrm{mg} / \mathrm{kg}$ pool size for all subjects (infants and adults), although plasma cholesterol concentrations were slightly lower in the infants. On the other hand, larger liver and blood volumes per body weight are present in infants compared with adults (22). Liver cholesterol contributes twice as much to the rapidly miscible cholesterol pool size as plasma cholesterol does. If anything, we therefore expect the rapidly miscible cholesterol pool size in preterm infants to be larger. Choice of larger or smaller pool sizes would lead to proportionally higher or lower estimates of cholesterol synthesis, respectively.

To our knowledge, four studies examining cholesterol synthesis in human infants as a function of dietary cholesterol intake have been reported (18-20,23). Using deuterium incorporation techniques, it has been estimated that fractional synthesis rate of cholesterol ranges from 2 to $11 \% / \mathrm{d}$ in infants, strongly depending on the type of feeding at 4 mo of age. The differences in fractional synthesis rates have been attributed to the quantity of dietary cholesterol, which was 3-fold higher for breast-fed infants than for those fed regular formulas. As expected, the quantity of cholesterol intake was found to be negatively associated with the fractional synthesis rate. Several studies in animals and humans already indicated that the rates of sterol synthesis are much higher in the fetus than in the adult when presented on a per-gram tissue basis [reviewed in (24)]. The high rates of fetal sterol synthesis may be related to high expression levels or activities of transcription factors, such as sterol regulatory element binding proteins (SREBP), although, to the best of our knowledge, no information has been published on their function during development (25).

Fat accumulates during the last trimester of intrauterine life and accounts for about $16 \%$ of the total weight at birth (26). Most fat is present in the form of white adipose tissue. Definite data on the contribution of de novo lipogenesis are not known. Studies indicate that the rate of hepatic fatty acid synthesis is substantial in the fetus (27-29). The fraction of de novo lipogenesis measured in this study in lipoprotein-palmitate in the premature infants varied between 0.9 and $11.9 \% / 12 \mathrm{~h}$. In adults on a normal Western diet, the fractional contribution to VLDL-palmitate equaled $<5 \%$, a value that may increase to nearly $30 \%$ during high carbohydrate intake (30). Our results in adult subjects are in line with these data. The fractional lipoprotein-palmitate synthesis found in premature infants in this small study was not related to birth weight, gestational age, or gender. The lack of a significant difference between the two groups might be related to the high variability. We performed a posthoc power calculation that showed that a sample size of 24 should be sufficient to test whether a significant difference $(p<0.05$, power $90 \%)$ is different between premature infants and adult controls. Hellerstein (31) suggested that lipogenesis in humans is a rudimentary metabolic process, possibly only of importance in the fetus; our data show that newly synthesized palmitate by the liver makes up a large part of the lipids that are present in the blood.

Total parenteral nutrition (TPN) was initiated at $24 \mathrm{~h}$ after birth and consisted of an amino acid mixture with glucose and a lipid emulsion. Hamilton et al. (32) showed that i.v. lipid emulsions in premature infants result in a marked increase in cholesterol synthesis. Furthermore, it is well known that infusing lipids down-regulates de novo lipogenesis. However, fatty acid synthesis and cholesterol synthesis rates were measured at a mean age of $50 \pm 7 \mathrm{~h}$ when exogenous lipid supply was still low $(0.8 \mathrm{~g} / \mathrm{kg} / \mathrm{d})$, making a large influence of TPN on these parameters unlikely. Furthermore, TPN did not equilibrate in the VLDL fraction after ultracentrifugation (data not shown). On the other hand, carbohydrates have a well-known stimulatory effect on de novo lipogenesis and subjects received mostly glucose during the course of the experiment. Even in this relatively stimulatory situation, hepatic de novo lipogenesis was low in both study groups, underscoring the conclusion that this pathway is not of major importance in premature infants.

De novo synthesis of fatty acids depends on the substrate availability of precursors of acetyl-CoA and on the activity of the acetyl-CoA carboxylase and the fatty acid synthase complex. The enrichments of the acetyl-CoA pool found in the premature infants was higher than in the adult subjects that received the $\left[1-{ }^{13} \mathrm{C}\right]$ acetate infusion at the same rate, indicating a decreased acetyl-CoA pool size or an increased flux through the acetyl-CoA pool that supplied the precursors for cholesterologenesis and lipogenesis. It is therefore unlikely that a relative deficiency in lipogenic precursors was present in the premature infants. The identity of acetyl-CoA pools for cholesterologenesis and lipogenesis, however, cannot be relied upon. Separate cytosolic acetyl-CoA could, in theory, have a similar enrichment in distinct cholesterologenic and lipogenic precursor pools. Enriching the acetyl-CoA pool might theoretically influence synthesis rates if they are precursor driven. However, in this study we found no correlation between acetylCoA pool enrichments and synthesis rates. This does not rule out some effect of label infusion, but does make it rather unlikely.

In this study, we used adult subjects as a control group. Of course, this is not ideal, because cholesterol pool sizes and VLDL turnover rates might be different in adults and premature infants. Furthermore, dietary intake was not completely similar with a higher amount of lipids given to the adult subjects. However, because it was impossible to find parents of healthy newborn infants willing to let their baby be subjected to i.v. infusions and blood sampling, this experimental setup proved to be not feasible. Furthermore, comparing premature infants with adult subjects does provide information on whether hepatic de novo lipogenesis and cholesterologenesis are important in preterm infants, because values in adults have been validated for their importance in lipid accumulation and cholesterol metabolism.

All mothers, except one, received antenatal corticosteroid therapy to promote fetal maturation, especially of the lungs. 
This treatment has been shown to reduce mortality, respiratory distress syndrome, and intraventricular haemorrhage in premature infants. Several animal and human studies (32-34) have indicated that the effect of glucocorticoids on lipogenesis may be organ-specific, in favor of lipogenesis in the lung in comparison to that in the liver.

In summary, the present data show that cholesterologenesis is relatively high in premature infants. Furthermore, our data suggest that hepatic de novo lipogenesis is not a major contributor to fat accumulation in the premature infant shortly after birth. We speculate that extrahepatic lipogenesis might be of more importance for the lipid accumulation in the fetus during the last trimester of pregnancy. It has been postulated, on the basis of animal and human studies $(35,36)$, that long-lasting effects of early nutrition may lead to a disturbed lipid metabolism later in life and development of chronic diseases. These effects may be caused by persistent changes in lipid metabolism that are induced by early feeding. With MIDA it has become possible to study short-term effects of dietary cholesterol and fatty acid composition in formulas and in human milk on synthesis and turnover of lipids, thus providing a clue on how early nutrition may affect these parameters.

\section{REFERENCES}

1. Porter JA, Young KE, Beachy PA 1996 Cholesterol modification of hedgehog signaling proteins in animal development. Science 274:255-259

2. Schoonjans K, Staels B, Auwerx J 1996 Role of the peroxisome proliferator-activated receptor (PPAR) in mediating the effects of fibrates and fatty acids on gene expression. J Lipid Res 37:907-925

3. Wilentz RE, Witters LA, Pizer ES 2000 Lipogenic enzymes fatty acid synthase and acetyl-coenzyme A carboxylase are coexpressed with sterol regulatory element binding protein and Ki-67 in fetal tissues. Pediatr Dev Pathol 3:525-531

4. Coleman RA 1989 The role of the placenta in lipid metabolism and transport. Semin Perinatol 13:180-191

5. Dutta-Roy AK 2000 Transport mechanisms for long-chain polyunsaturated fatty acids in the human placenta. Am J Clin Nutr 71:315S-322S

6. Herrera E, Bonet B, Lasunción MA 1998 Maternal-fetal transfer of lipid metabolites. In: Polin RA, Fox WW (eds) Fetal and Neonatal Physiology. WB Saunders, Philadelphia, pp 447-458

7. Van Aerde JE, Feldman M, Clandinin MT 1998 Accretion of lipid in the fetus and newborn. In: Polin RA, Fox WW (eds) Fetal and Neonatal Physiology. WB Saunders, Philadelphia, pp 458-477

8. Hellerstein MK, Schwarz JM, Neese RA 1996 Regulation of hepatic de novo lipogenesis in humans. Annu Rev Nutr 16:523-557

9. Barker DJ, Osmond C 1986 Diet and coronary heart disease in England and Wales during and after the second world war. J Epidemiol Community Health 40:37-44

10. McGill Jr HC, Mott GE, Lewis DS, McMahan CA, Jackson EM 1996 Early determinants of adult metabolic regulation: effects of infant nutrition on adult lipid and lipoprotein metabolism. Nutr Rev 54:S31-S40

11. Neese RA, Faix D, Kletke C, Wu K, Wang AC, Shackleton CH, Hellerstein MK 1993 Measurement of endogenous synthesis of plasma cholesterol in rats and humans using MIDA. Am J Physiol 264:E136-E147

12. Wiegman $\mathrm{CH}$, Bandsma RHJ, Ouwens M, van der Sluijs FH, Havinga R, Boer T, Reijngoud DJ, Romijn JA, Kuipers F 2003 Hepatic VLDL production in ob/ob mice is not stimulated by massive de novo lipogenesis but is less sensitive to the suppressive effects of insulin. Diabetes 52:1081-1089

13. Beil FU, Grundy SM 1980 Studies on plasma lipoproteins during absorption of exogenous lecithin in man. J Lipid Res 21:525-536

14. Hellerstein MK, Neese RA 1992 Mass isotopomer distribution analysis: a technique for measuring biosynthesis and turnover of polymers. Am J Physiol 263:E988-E1001

15. Hellerstein MK, Christiansen M, Kaempfer S, Kletke C, Wu K, Reid JS, Mulligan K, Hellerstein NS, Shackleton CH 1991 Measurement of de novo hepatic lipogenesis in humans using stable isotopes. J Clin Invest 87:1841-1852

16. Hellerstein MK, Neese RA, Schwarz JM 1993 Model for measuring absolute rates of hepatic de novo lipogenesis and reesterification of free fatty acids. Am J Physio 265:E814-E820

17. Bunt JE, Zimmermann LJ, Wattimena JL, van Beek RH, Sauer PJ, Carnielli VP 1998 Endogenous surfactant turnover in premature infants measured with stable isotopes. Am J Respir Crit Care Med 157:810-814

18. Wong WW, Hachey DL, Insull W, Opekun AR, Klein PD 1993 Effect of dietary cholesterol on cholesterol synthesis in breast-fed and formula-fed infants. J Lipid Res 34:1403-1411

19. Cruz ML, Wong WW, Mimouni F, Hachey DL, Setchell KD, Klein PD, Tsang RC 1994 Effects of infant nutrition on cholesterol synthesis rates. Pediatr Res 35:135-140

20. Bayley TM, Alasmi M, Thorkelson T, Krug-Wispe S, Jones PJ, Bulani JL, Tsang RC 1998 Influence of formula versus breast milk on cholesterol synthesis rates in four-month-old infants. Pediatr Res 44:60-67

21. Di Buono M, Jones PJ, Beaumier L, Wykes LJ 2000 Comparison of deuterium incorporation and mass isotopomer distribution analysis for measurement of human cholesterol biosynthesis. J Lipid Res 41:1516-1523

22. Behrman RE, Kliegman RM, Jenson HB. 1996 Nelson Textbook of Pediatrics. WB Saunders, Philadelphia, pp 1126

23. Bayley TM, Alasmi M, Thorkelson T, Jones PJ, Corcoran J, Krug-Wispe S, Tsang RC 2002 Longer term effects of early dietary cholesterol level on synthesis and circulating cholesterol concentrations in human infants. Metabolism 51:25-33

24. Dietschy JM, Turley SD, Spady DK 1993 Role of liver in the maintenance of cholesterol and low density lipoprotein homeostasis in different animal species, including humans. J Lipid Res 34:1637-1659

25. Brown MS, Goldstein JL 1999 A proteolytic pathway that controls the cholesterol content of membranes, cells, and blood. Proc Natl Acad Sci U S A 96:11041-11048

26. Noble RC, Shand JH, Calvert DT 1982 The role of the placenta in the supply of essential fatty acids to the fetal sheep: studies of lipid compositions at term. Placenta $3: 287-295$

27. Zimmermann T, Hummel L, Moller U, Kinzl U 1979 Oxidation and synthesis of fatty acids in human and rat placental and fetal tissues. Biol Neonate 36:109-112

28. Zimmermann T, Hummel L 1978 Studies on fatty acid synthesis in maternal and fetal rats. Acta Biol Med Ger 37:223-227

29. Miguel SG, Abraham S 1976 Effect of maternal diet on fetal hepatic lipogenesis. Biochim Biophys Acta 424:213-234

30. Schwarz JM, Neese RA, Turner S, Dare D, Hellerstein MK 1995 Short-term alterations in carbohydrate energy intake in humans. Striking effects on hepatic glucose production, de novo lipogenesis, lipolysis and whole-body fuel selection. J Clin Invest 96:2735-2743

31. Hellerstein MK 1995 Methods for measurement of fatty acid and cholesterol metabolism. Curr Opin Lipidol 6:172-181

32. Hamilton JJ, Phang M, Innis SM 1992 Elevation of plasma lathosterol, as an indicator of increased cholesterol synthesis, in premature (23-32 weeks gestation) infants given Intralipid. Pediatr Res 31:186-192

33. Beneke S, Rooney SA 2001 Glucocorticoids regulate expression of the fatty acid synthase gene in fetal rat type II cells. Biochim Biophys Acta 1534:56-63

34. Wagle S, Bui A, Ballard PL, Shuman H, Gonzales J, Gonzales LW 1999 Hormonal regulation and cellular localization of fatty acid synthase in human fetal lung. Am J Physiol 277:L381-L390

35. Fall CH, Barker DJ, Osmond C, Winter PD, Clark PM, Hales CN 1992 Relation of infant feeding to adult serum cholesterol concentration and death from ischaemic heart disease. BMJ 304:801-805

36. McGill HC Jr, Mott GE, Lewis DS, McMahan CA, Jackson EM 1996 Early determinants of adult metabolic regulation: effects of infant nutrition on adult lipid and lipoprotein metabolism. Nutr Rev 54:S31-S40 